\title{
Is Hand Massage with the Preferred Aroma Oil better than Lavender on Stress and Sleep for Long-term Care Facility Residents?
}

\author{
Park, Mi Jung ${ }^{1}$. Park, Heeok ${ }^{2}$ \\ ${ }^{1}$ Researcher, Keimyung University, Research Institute of Nursing Science, Daegu, Korea \\ ${ }^{2}$ Associate Professor, College of Nursing · Research Institute of Nursing Science, Keimyung University, Daegu, Korea
}

\begin{abstract}
Purpose: This study aimed to compare the effects of hand massage with the preferred aroma oil to those of hand massage with lavender oil on stress and sleep in residents at a long-term care facility. Methods: A group randomized controlled design was used. Of the 37 participants, 19 were assigned to the experimental group(hand massage with the preferred aroma oil) and 18 to the control group(hand massage with lavender oil). Data collection was performed from Nov. 262016 to Jan. 27 2017. Hand massage was offered for 5 minutes each side 3 times a week for a total of 12 sessions over 4 weeks. Stress was measured using the Perceived Stress Questionnaire and sleep was measured using the Verran and Snyder-Halpern Sleep Scale. Results: Subjects in the experimental group showed significantly lower stress levels (physical stress, $\mathrm{t}=-2.10, p=.048$; psychological stress, $\mathrm{t}=-4.41, p<.001$ ) and sleep $(\mathrm{t}=3.37, p=.002)$ than those in the control group. Conclusion: These results suggest that aromatherapy with hand massage should consider client aroma preference for elderly at long-term care facilities in the future.
\end{abstract}

Key Words: Massage; Aromatherapy; Stress; Sleep; Long-term care

\section{INTRODUCTION}

Residents in Long-Term Care (LTC) facilities experience difficulties adjusting to new environments because of changes in social roles and life patterns and loss of autonomy and personal lives [1]. Choi and Yang [2] reported that almost $30 \%$ of residents at LTC facilities show stress caused by their ailments, residents' deaths, divorce, and others. Stress also increases when residents are admitted to the facility by their families without enough explanation and understanding [3]. Because of this stress, residents at LTC facilities exhibit hypertension, gastrointestinal disease, itching, and sleeplessness more than others [4].

Sleep is an important factor for a healthy life. Sufficient sleep increases a person's quality of life, but disturbance in sleeping patterns increases fatigue and attention deficit, and risk of falls also decreases activities of daily living and quality of life [5]. Almost $60.1 \%$ of residents at LTC facilities show sleeplessness in South Korea, and $18.5 \%$ at LTC facilities show low sleep quality [6]. Lack of sleeping is often considered as normal in the aging process, but it negatively affects physical function, safety, and quality of life $[6,7]$.

To improve stress and sleeping among residents at LTC facilities, medications are often provided, but they bring negative effects such as the possibility of drug abuse, medication dependence, cognition deficit, and so on so that the non-pharmacological methods need to be provided preferentially [8]. Among the non-pharmacological methods, hand massage with aroma oil helps relaxation [9]. Hand massage is beneficial because it is easily applied and immediately effective [9]. Aroma hand massage is generally reported effective at improving physical/mental stability, relieving stress, reducing depression, and improving sleep quality [7].

There are various types of aroma oils and more than 300 types of aroma oils can be used on the human body, but among them, only around 60 types are mainly used in

Corresponding author: Park, Heeok https://orcid.org/0000-0002-8194-0373

College of Nursing, Keimyung University, 1095 Dalgubeol-daero, Dalseo-gu, Daegu 42601, Korea.

Tel: +8-53-580-3924, Fax: +82-53-580-3916, E-mail: hopark@kmu.ac.kr

Received: Jan 17, 2019 / Revised: Feb 26, 2019 / Accepted: Mar 14, 2019

This is an open access article distributed under the terms of the Creative Commons Attribution Non-Commercial License (http://creativecommons.org/licenses/ by-nc/3.0), which permits unrestricted non-commercial use, distribution, and reproduction in any medium, provided the original work is properly cited. 
complementary therapy [10]. Among them, aroma oils including the 10 types of lavender, Roman chamomile, bergamot, clary sage, geranium, sweet orange, everlasting, neroli, frankincense, and sandalwood were effective in soothing, stabilization, and relaxation according to previous research on aromatherapy $[7,9,11]$. First, lavender and Roman chamomile were used in previous research on itchiness and sleeping $[7,11]$ as they have relaxing and soothing effects. In particular, lavender is the least toxic oil, has fewer adverse effects among all aroma oils, and is one of the aromas most preferred by elderly people [9]. Additionally, it was observed that geranium, sweet orange, bergamot, and sandalwood are effective in relieving depression, anxiety, and stress [12], and that everlasting is effective for burnout, neroli for fatigue, and frankincense for end-of-life agitation [13].

Previous studies reported that hand massage with aroma oil was effective for improving stress and sleeping in residents staying at LTC facilities $[7,14]$. Those studies provided hand massage for more than two weeks, and the aroma oil consisted of lavender, bergamot, geranium, peppermint, and so on selected by the researchers. Kang and Kim [11] investigated the effects of hand massage with aroma oil including lavender, geranium, and Roman chamomile on stress, depression, and itching in patients with hemodialysis for four weeks, and the stress, depression, and itching were improved. However, in aromatherapy hand massage, all the subjects were offered the same aroma oil, which was selected by the researcher, so in the study of Kang and Kim [11], some subjects rejected the fragrance of the aroma oil during the intervention process, and Park [15] reported experiencing many difficulties because of the intervention method that did not consider personal characteristics of individual subjects, as some subjects experienced dizziness and headache, indicating that it is necessary to consider the preferences of subjects regarding aroma oil.

Park [16] reported that Koreans in their 20's 60's mostly prefer lavender and some prefer rosemary, showing that the preferences for aroma oil can vary depending on age and gender. As such, the previous research showed that subjects had different preferences for aroma oil; some expressed displeasure when offered an aroma oil that they did not prefer. Thus, when applying aromatherapy, it is important to ask subjects about their preferred aroma.

Thus, the current study aimed to determine each participant's preferred aroma oil and test the effect of hand massage with the preferred aroma oil on stress and sleep in residents at an LTC facility. The purpose of this study was to compare the differences in stress and sleep changes be- tween the experimental and control group among residents at an LTC facility.

\section{METHODS}

\section{Study Design and Samples}

A group randomized controlled trial design was used. The current study was performed to compare the effects of hand massage with a preferred aroma oil and hand massage with lavender oil on stress and sleeping in residents at an LTC facility.

A total of 37 residents at one LTC facility in Daegu-city, South Korea, participated in the current study. Inclusion criteria were as follows: being 65 years or older, having complaints of stress and sleeping problems, no numbness in both hands, being communicative and able to understand the questionnaires. Exclusion criteria were having prior experience with aroma oil, having disease related to the nose such as rhinitis or not being able to smell, and having an allergic response to aroma oil such as pruritus or edema. Residents at the LTC facility were asked if they were "Having sleeping problems" by the researcher and those that answered "yes" were included.

According to a coin toss, residents staying on the second floor were assigned to the experimental group and those on the third floor to the control group, so group randomization was used to assign the subjects to the experimental or control group. The number of participants in this study was determined using $G^{*}$ Power 3.1.9.2, independent t-test, power .80 , effect size .50 , and $\alpha=.05$ and the effect size was determined based on the Kim study [17]. Based on the calculation, a total of 34 participants (17 for each group) was required; after assuming a 10\% dropout rate, a total of 38 participants (19 for each group) was determined. Finally, a total of 37 participants (19 and 18 in the experimental and control groups, respectively) were completed in this study after one participant dropped from the control group; discharge (Figure 1).

\section{Measurements}

1) Stress and sleep were included for the measurements.

(1) Stress

Stress was measured using the Perceived Stress Questionnaire (PSQ). The PSQ was developed by Park [18] to measure the stress level of adults and it has been used to measure older adults' stress in many previous studies. It includes two areas: physical (15 items) and psychological (15 items). Each item is rated using a four-point Likert 


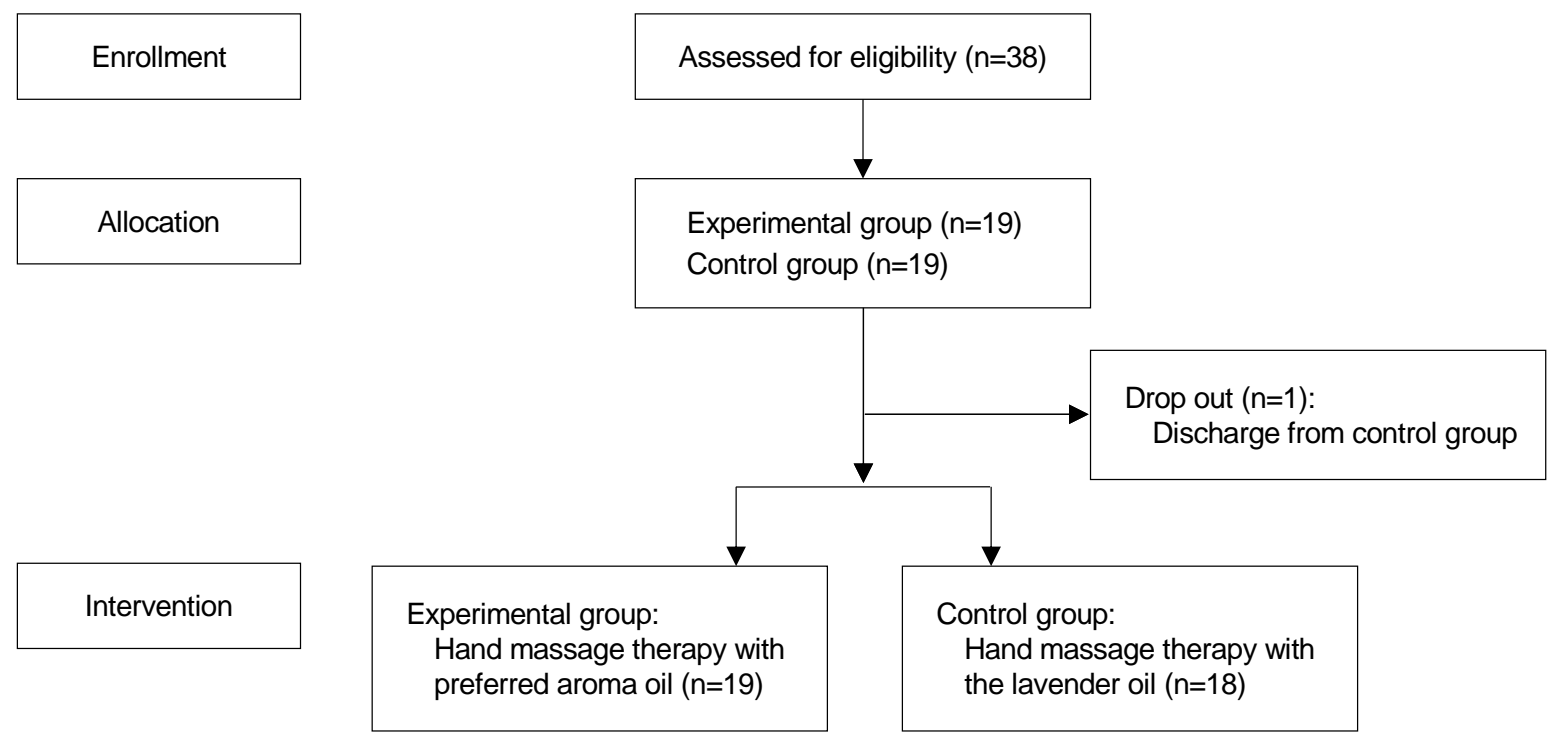

Figure 1. Flow diagram of the participants selection $(N=19)$.

scale of $0 \sim 3$. The four-point scale allots 0 points to "never", 1 point to "sometimes", 2 points to "fairly often", and 3 points to "very often". A higher score means higher stress. When the measure was developed, Cronbach's $\alpha=.86$ [18]; in this study, Cronbach's $\alpha=.83$ (physical domain=.66, psychological domain=.81). The author of the PSQ was contacted by email for permission to use the questionnaire, but no response was received.

\section{(2) Sleep}

Sleep was measured using a measuring tool that was revised and adapted as a Korean-style sleep scale by Oh et al.[19] from the Verran and Snyder-Halpern (VSH) Sleep Scale developed by Snyder-Halpern and Verran [20]. The tool measures sleep status for the most recent week consisting of a total of 15 questions; questions no. 11 and no. 13 are reverse-questions. It uses a four-point scale allotting 4 points to "never feel," 3 points to "occasionally feel," 2 points to "often feel," and 1 point to "always feel." The lowest score is 15 points while the highest score is 60 points. This means that the higher the score, the better the sleep status. When the tool was developed, it showed Cronbach's $\alpha=.79$ [20], while the study of Oh et al. [19] showed Cronbach's $\alpha=.75$; this study showed Cronbach's $\alpha=.77$. The Korean version of the VSH was approved by the researchers for use in this study by e-mail.

\section{Data Collection and Procedure}

The Primary Investigator (PI) initially contacted the directors of nursing or head nurses at the six largest LTC facilities in Daegu city by phone. Only one LTC facility allowed the PI to visit to introduce the study. Subsequently, the PI visited the LTC facility to present the study to the residents using a PowerPoint presentation and printed handouts during the patients' free time for 20 minutes. The patients attended the presentation in their rooms. The facility consisted of approximately 180 beds and 50 nursing staff.

After the presentation, informed consent was obtained if residents agreed to participate, and data collection was started. The experimental and control group were assigned to patients who were residing on different floors from each other to prevent the experiment from spreading across the LTC facility. A total of 19 patients were assigned to the experimental group, while the other 19 patients were assigned to the control group. One patient dropped out of the control group due to being discharged. Patients' characteristics and disease severities were similar between the groups and their mobility statuses ranged from bed-ridden to mobile in bed. The patients' characteristics were answered by the PI using the questionnaires. The nursing staff caring for the patients remained on the same floor during the entire data collection period to avoid contamination of the treatment given to the control group.

The experimental group participated for 4 weeks from Nov. 26 to Dec. 24, 2016 and after the treatment to the experimental group was finished, the control group participated from Dec. 26 to Jan. 27 2017. Residents in the experimental group were provided with a hand massage with preferred aroma oil. First, the PI introduced the 10 aroma oil samples to each subject and proposed that the subjects 
select their preferred aroma oil. The 10 aroma oils presented to the subjects were as follows: lavender, Roman chamomile, bergamot, clary sage, geranium, sweet orange, everlasting, sandalwood, neroli, and frankincense. After the sample oil trial, residents individually selected the two most preferred types of aroma oil, as suggested by previous studies related to aroma therapy [21], and these were mixed with $30 \mathrm{cc}$ of jojoba oil for $2 \%$ (6 drops for each essential oil). Meanwhile, residents in the control group were provided with the hand massage with lavender, which was mixed with $30 \mathrm{cc}$ of jojoba oil.

The experimental group was offered aroma hand massage therapy with their preferred aroma oil, while the control group was provided with aroma hand massage therapy with the lavender oil, which is related to relaxation. Although different aroma oils were applied to the two groups, the same hand massage skill was applied to both groups, that is, the hand massage part from the aromatherapy massage video program developed by the Korean Nurses Association [22]. The PI completed the general instructor course of the international association of aromatherapists and obtained the aroma instructor certificate (Certificate NO. IAA-A1-160204). The PI trained two nursing graduate students as the research assistants using the aroma video, and they practiced the aroma hand massage for 3 days for the double check.

Aroma hand massage was offered by the researcher and two research assistants to each subject at an LTC facility from $6 \sim 8$ p.m., avoiding nursing and meal times. Furthermore, it was offered at the subject's room or a place where the subject felt comfortable with the subject lying down or sitting up. The time and number of sessions of hand massage were determined by referring to the study of Kang and Kim [11], and a total of 12 sessions of hand massage were offered for 5 minutes per hand and 10 minutes in total, three times a week, for 4 weeks (Monday, Wednesday, and Friday). The PI was certified as an aroma lecturer, and the research assistants were graduate students and nurses trained to provide the hand massage by the PI.

For the data collection, the PI and research assistants assessed the residents' demographic data, preferred aroma oil, stress, and sleep level 1 day prior to the first intervention for the pre-test and on the day after the final intervention for the post-test in the residents' rooms. When the residents showed discomfort completing the questionnaires because of physical disabilities, the researchers helped them answer the questionnaires (e.g., read the questions to them). The pre- and post-tests were performed between 3:00 and 5:00 pm to avoid nursing care time or at lunch time for approximately 20 minutes.

\section{Ethical Consideration}

The current study was approved by the Keimyung University IRB board (IRB NO. 40525-201610-HR-110-01) and the written permission was obtained before conducting the study. An explanation of informed consent was offered to the residents by the PI and the written consent of each resident was obtained. The PI explained the purpose, contents, advantages, and risks of this study to the participants. The possibility of withdrawal and anonymity were also explained.

\section{Data Analysis}

The collected data were analyzed using the software SPSS/WIN 18.0 (IBM Corp., Armonk, NY, USA) according to the purpose of the study. Descriptive statistics were used to describe subjects' characteristics. The Kolmogorov-Smirnov test was used to test the normal distribution of stress and sleep data. Independent t-tests, a $x^{2}$ test, and Fisher's exact tests were used to compare the difference in stress and sleep changes between the experimental and control group. The significance was evaluated at $p<.050$.

\section{RESULTS}

\section{Participants' Characteristics}

Participants' characteristics are presented in Table 1. Most participants in the experimental group were more than age $75(52.6 \%)$, were female $(78.9 \%)$, had no education $(36.8 \%)$, were bereaved $(68.4 \%)$ and had less than one family visit per four weeks (52.6\%). Most participants in the experimental group had hypertension/diabetes mellitus (43.3\%) and chronic pain (52.6\%) and were using medication such as antidiabetic agents $(22.2 \%)$.

Most participants in the control group were older than $75(72.2 \%)$, were female (77.8\%), had no education (38.9\%), were bereaved $(66.7 \%)$, and had family visit less than once per four weeks $(38.9 \%)$. Most participants in the control group had hypertension/diabetes mellitus $(52.6 \%)$ and chronic pain $(66.7 \%)$ and were using medication such as antihypertensive $(23.9 \%)$ and others $(23.9 \%)$. There were no significant differences in participants' characteristics between the experimental and control group (Table 1).

Figure 2 shows preferred aroma oil in the experimental group. The most preferred aroma oil by the experimental group participants were sweet orange and clary sage (18.5\% each), while Roman chamomile was least preferred (5.2\%), and there was no participant who preferred lavender. 
Park, MJ · Park, H

Table 1. Differences in Participants' Characteristics between the Experimental and Control Group

\begin{tabular}{|c|c|c|c|c|c|}
\hline \multirow{2}{*}{ Characteristics } & \multirow{2}{*}{ Categories } & \multirow{2}{*}{$\begin{array}{c}\text { Exp. }(n=19) \\
n(\%)\end{array}$} & \multirow{2}{*}{$\frac{\text { Cont. }(n=18)}{n(\%)}$} & \multirow{2}{*}{$x^{2}$ or Fisher ${ }^{\dagger}$} & \multirow{2}{*}{$p$} \\
\hline & & & & & \\
\hline \multirow[t]{2}{*}{ Age (year) } & $\leq 74$ & $9(47.4)$ & $5(27.8)$ & 1.51 & .219 \\
\hline & $\geq 75$ & $10(52.6)$ & $13(72.2)$ & & \\
\hline \multirow[t]{2}{*}{ Gender } & Men & $4(21.1)$ & $4(22.2)$ & $0.01^{\dagger}$ & .621 \\
\hline & Women & 15 (78.9) & $14(77.8)$ & & \\
\hline \multirow{3}{*}{ Education } & Uneducated & $7(36.8)$ & $7(38.9)$ & 0.06 & .969 \\
\hline & Elementary school & $6(31.6)$ & $6(33.3)$ & & \\
\hline & Above middle school & $6(31.6)$ & $5(27.8)$ & & \\
\hline \multirow[t]{3}{*}{ Marital status } & Married & $6(31.6)$ & $4(22.2)$ & $2.06^{\dagger}$ & .484 \\
\hline & Bereaved & $13(68.4)$ & $12(66.7)$ & & \\
\hline & Divorce or unmarried & $0(0.0)$ & $2(11.1)$ & & \\
\hline \multirow[t]{4}{*}{ Family visit } & Once a week & $3(13.8)$ & $6(33.3)$ & $1.78^{\dagger}$ & .719 \\
\hline & Once every 2 3 weeks & $4(21.1)$ & $3(16.7)$ & & \\
\hline & Less than once every 4 weeks & $10(52.6)$ & 7 (38.9) & & \\
\hline & Daily & $2(10.5)$ & $2(11.1)$ & & \\
\hline \multirow{6}{*}{$\begin{array}{l}\text { Disease } \\
\text { (double answers) }\end{array}$} & Hypertension/Diabetes mellitus & $13(43.3)$ & $20(52.6)$ & $2.15^{\dagger}$ & .932 \\
\hline & Cardiovascular disease & $6(20.0)$ & $6(15.8)$ & & \\
\hline & Musculoskeletal disease & $6(20.0)$ & $6(15.8)$ & & \\
\hline & Digestive disease & $2(6.7)$ & $3(7.9)$ & & \\
\hline & Thyroid disease & $0(0.0)$ & $1(2.6)$ & & \\
\hline & None & $3(10.0)$ & $2(5.3)$ & & \\
\hline \multirow[t]{2}{*}{ Chronic pain } & Yes & $10(52.6)$ & $12(66.7)$ & 0.76 & .385 \\
\hline & No & $9(47.4)$ & $6(33.3)$ & & \\
\hline \multirow{6}{*}{$\begin{array}{l}\text { Medication } \\
\text { (double answers) }\end{array}$} & Analgesics & $7(19.4)$ & $8(17.4)$ & $2.31^{\dagger}$ & .839 \\
\hline & Antihypertensive & $6(16.7)$ & $11(23.9)$ & & \\
\hline & Antidiabetic agents & $8(22.2)$ & $9(19.6)$ & & \\
\hline & Sedative hypnotics & $6(16.7)$ & $5(10.9)$ & & \\
\hline & Etc. $^{\dagger}$ & $6(16.7)$ & $11(23.9)$ & & \\
\hline & None & $3(8.3)$ & $2(4.3)$ & & \\
\hline
\end{tabular}

Exp.=experimental group; Cont. $=$ control group; ${ }^{\dagger}$ Fisher's exact test; ${ }^{\dagger}$ Osteoporosis agents, thyroid hormones supplements, digestant, stool softener.

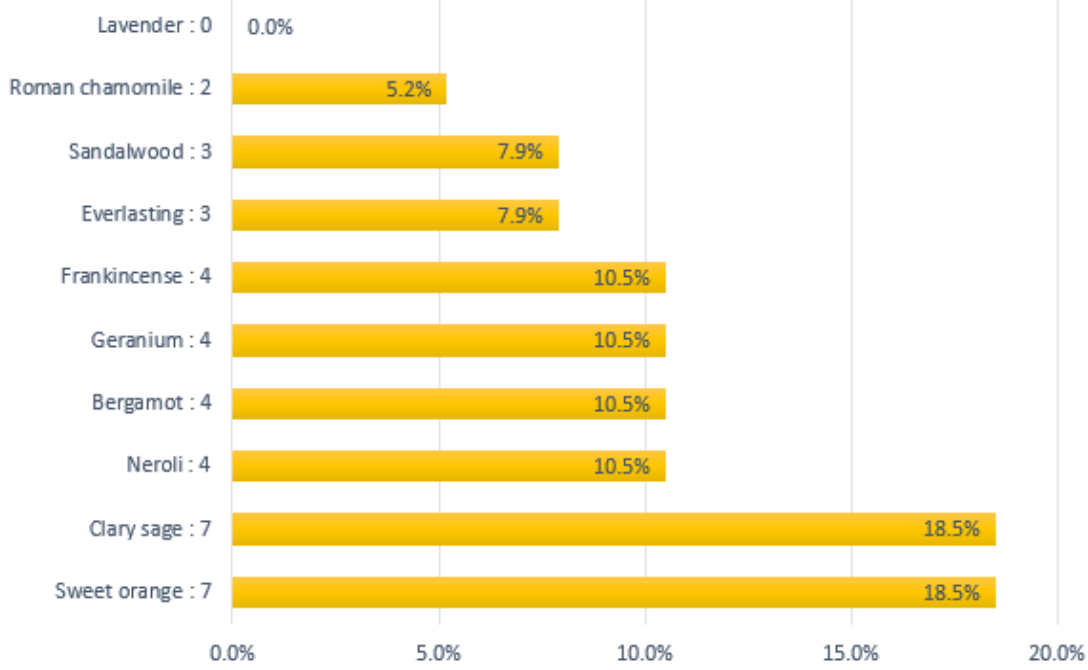

Figure 2. Preferred aroma oil in the experimental group $(N=19)$. 


\section{Homogeneity Test in Stress and Sleep between the Experimental and Control Group}

Homogeneity test in stress and sleep between the experimental and control group is shown in Table 2. There was no significant difference in stress and sleep between the groups.

\section{Difference in Stress and Sleep Changes between the Experimental and Control Group}

The stress and sleep values were normally distributed. Difference in stress and sleep changes between the experimental and control group are presented in Table 3. The mean level of stress prior to the intervention in the experimental group was $14.84 \pm 4.06$, and that decreased to $9.37 \pm 2.73$, and the difference in stress level between before and after the intervention in the experimental group was significant $(t=7.75, p<.001)$. The mean level of stress prior to the intervention in the control group was 18.06 and decreased to 17.94, and the difference in stress level between before and after the intervention in the control group was not significant $(t=0.08, p=.935)$. The difference in the stress between the experimental and control groups after the intervention was significant $(t=-3.51, p=.002)$.
The mean level of sleep prior to the intervention in the experimental group was $44.37 \pm 4.19$ and increased to 47.05 \pm 4.35 , and the difference in sleep level between before and after the intervention in the experimental group was significant $(t=-4.57, p<.001)$. The mean level of sleep prior to the intervention in the control group was $43.94 \pm 5.68$ and increased to $44.00 \pm 5.20$, and the difference in sleep level between before and after the intervention in the control group was not significant $(\mathrm{t}=-0.11, p=.914)$. The difference in the sleep between the experimental and control groups after the intervention was significant $(\mathrm{t}=3.37, p=.002)$.

\section{DISCUSSION}

The current study tested the effects of hand massage with preferred aroma oil on stress and sleep for residents at an LTC facility and showed the hand massage with preferred aroma oil improved stress and sleep more than the lavender oil.

From the results of this study, it was observed that among the 10 aroma oils related to soothing, the participants in the experimental group most preferred sweet orange and clary sage at $18.5 \%$ each, and there was no participant who preferred lavender. These results are not consistent with Park [16] who reported that lavender and

Table 2. Homogeneity Test for Stress and Sleep between the Experimental and Control Group

$(N=37)$

\begin{tabular}{|c|c|c|c|c|}
\hline \multirow{2}{*}{ Variables } & Exp. $(n=19)$ & Cont. $(n=18)$ & \multirow{2}{*}{$\mathrm{t}$} & \multirow{2}{*}{$p$} \\
\hline & $\mathrm{M} \pm \mathrm{SD}$ & $\mathrm{M} \pm \mathrm{SD}$ & & \\
\hline \multicolumn{5}{|l|}{ Stress } \\
\hline Total & $14.84 \pm 4.06$ & $18.06 \pm 8.22$ & -1.49 & .148 \\
\hline Psychological & $7.26 \pm 2.92$ & $8.50 \pm 4.49$ & -0.99 & .332 \\
\hline Physical & $7.58 \pm 2.76$ & $9.56 \pm 4.23$ & -1.69 & .099 \\
\hline Sleep & $44.37 \pm 4.19$ & $43.94 \pm 5.68$ & 0.26 & .797 \\
\hline
\end{tabular}

Exp.=experimental group; Cont. $=$ control group.

Table 3. Differences in Stress and Sleep Changes between the Two Groups

\begin{tabular}{|c|c|c|c|c|c|c|c|c|c|}
\hline \multirow{2}{*}{ Variables } & \multirow{2}{*}{ Categories } & \multirow{2}{*}{ Group } & Pretest & Posttest & \multirow{2}{*}{$t$} & \multirow{2}{*}{$p$} & Difference & \multirow{2}{*}{$\mathrm{t}$} & \multirow{2}{*}{$p$} \\
\hline & & & $\mathrm{M} \pm \mathrm{SD}$ & $\mathrm{M} \pm \mathrm{SD}$ & & & $\mathrm{M} \pm \mathrm{SD}$ & & \\
\hline \multirow[t]{6}{*}{ Stress } & Total & Exp. $(n=19)$ & $14.84 \pm 4.06$ & $9.37 \pm 2.73$ & 7.75 & $<.001$ & $-5.47 \pm 3.08$ & -3.51 & .002 \\
\hline & & Cont. $(n=18)$ & $18.06 \pm 8.22$ & $17.94 \pm 8.14$ & 0.08 & .935 & $-0.11 \pm 5.74$ & & \\
\hline & Psychological & Exp. $(n=19)$ & $7.26 \pm 2.92$ & $4.21 \pm 1.78$ & 6.20 & $<.001$ & $-3.05 \pm 2.15$ & -2.10 & .048 \\
\hline & & Cont. $(n=18)$ & $8.50 \pm 4.49$ & $8.44 \pm 5.38$ & 0.04 & .967 & $-0.06 \pm 5.68$ & & \\
\hline & Physical & Exp. $(n=19)$ & $7.58 \pm 2.76$ & $5.16 \pm 1.46$ & 4.76 & $<.001$ & $-2.42 \pm 2.22$ & -4.41 & $<.001$ \\
\hline & & Cont. $(n=18)$ & $9.56 \pm 4.23$ & $9.50 \pm 4.13$ & 0.33 & .749 & $-0.06 \pm 0.73$ & & \\
\hline \multirow[t]{2}{*}{ Sleep } & & Exp. $(n=19)$ & $44.37 \pm 4.19$ & $47.05 \pm 4.35$ & -4.57 & $<.001$ & $2.68 \pm 2.56$ & 3.37 & .002 \\
\hline & & Cont. $(n=18)$ & $43.94 \pm 5.68$ & $44.00 \pm 5.20$ & -0.11 & .914 & $0.06 \pm 2.16$ & & \\
\hline
\end{tabular}

Exp.=experimental group; Cont. $=$ control group. 
rosemary were most preferred in a survey of adults on preference for aroma oils. Therefore, efforts need to be made to find out the subject's aroma oil preference when applying a nursing intervention as the preferred aroma oil can vary depending on the age, gender, and health status of the patient. Moreover, in this study, aroma hand massage including two types of aroma oil was consistently applied for 4 weeks depending on the subject's preference during experimental treatment. However, as the preference and status of the patient can change over time, it is necessary to consistently assess the aroma oil preference throughout treatment.

In this study, stress was improved significantly in the preferred aroma oil group but not in the lavender oil group. Tang and Tse [23] provided self-administered home-based aromatherapy for four weeks with inhalation of lavender and bergamot oil blending for community-dwelling older adults and reported older adults' stress was improved. Toda and Morimoto [24] also provided only lavender oil inhalation once for students, and their Chromogranin A was improved. lavender in those studies affected the cerebrum, which secretes serotonin, reducing tension and concern, and finally brings emotional and muscle relaxation. On the other hand, Bikmoradi et al. [25] provided inhalation of lavender oil for two days for CABG patients to improve stress, but the stress was not significantly improved. In the study, the lack of improvement in stress was considered to be because of past negative memories related to lavender oil and also a short treatment period. Kang and Kim [11] provided lavender, geranium, and Roman chamomile for four weeks for hemodialysis patients, but some of the participants dropped from the study because of undesirable symptoms such as nausea and headache. In the current study, in the lavender group, stress improved but not significantly. In many previous studies, lavender was reported to help sedation and relaxation [26], but the oil needs to be provided according to the participants' preferences for the next studies and in clinical settings.

In this study, sleep improved significantly in the hand massage group with preferred oil compared to the lavender oil group. Lee [27] provided hand massage with lavender, Roman chamomile, and cypress for two weeks and found improved sleep for the Long-Term Care residents. Moeini et al. [28] also provided inhalation of lavender oil blending for CCU patients for only three days and improved their sleep. On the other hand, Lytle et al. [29] provided inhalation of lavender oil blending during one night to ICU patients, but sleep was not improved. They mentioned no improvement of sleep in the ICU patients was because of the small sample size of the study and only one time of treatment.

There were no consistent results of testing the aroma therapy using the lavender oil. In the current study, sleep level of LTC facility residents improved after the intervention, but the change in the lavender group was not significant. Residents in the lavender group did not complain of discomfort during the study, but the residents in the preferred oil group showed active interests in participating in this study. To meet the residents' preferences of aroma oil, consistent assessment of aroma oil and monitoring of health outcome such as sleep is needed. The fragrance of an aroma oil reminds one of past personal experiences and feelings, creating individual effects [30]. Using the preferred aroma oil based on patient taste would maximize the effect of the intervention. Most patients in LTC facilities have limited opportunities to select any kind of intervention, so the findings of this study would be meaningful to reinforce the importance of personal selection for LTC residents. Meanwhile, although stress and sleep in the control group did not improve significantly between the pre- and post-test, stress decreased and sleep increased slightly. Because only 12 sessions of hand massage with Lavender for 4 weeks was provided to the control group, we would suggest another study to test the ability of hand massage with lavender offered in more numerous sessions to improve stress and sleep.

In the preferred oil group, the most commonly preferred were sweet orange, clary sage, neroli, bergamot, geranium, and others. Lavender was not selected by the residents as the preferred oil in this study. In Park's study [16], the most preferred aroma oils were reported to be lavender and rosemary. The preferred oils in the previous studies were not consistent with each other or with the results of the current study. Thus, the preferred oil needs to be assessed with regular basis for the intervention and applied for the individual resident.

Limitations of this study include the small sample size and one place for data collection. The current study was performed at one facility, so the findings cannot be generalized. Neurologic disorders that could affect sleep disturbances were not assessed for at baseline; this must be considered in future studies. Additionally, stress and sleep in this study were measured using only subjective questionnaires; both must be measured objectively in future studies such as via cortisol levels or observed sleep quality and hours to verify the effects of the intervention. In addition, the participants were not totally blinded to the intervention because researchers performed the intervention and data collection; therefore, the lack of allocation concealment may have introduced bias. To consistently reflect 
the preference of the patient, the patient's preference concerning aroma oil needs to be consistently assessed through the period of experimental treatment and each session of treatment needs to be provided accordingly. Therefore, this should be considered in further studies and clinical settings on aroma oil.

\section{CONCLUSION}

The current study showed that the hand massage with preferred aroma oil improved stress and sleep for the LTC facility residents more than the lavender aroma oil. The preferred aroma oils mainly included were sweet orange, clary sage, neroli, bergamot, geranium, and others. Hand massage with the preferred aroma oil was effective on stress and sleep compared to the lavender oil in long-term care facility residents. Health professionals could consider aroma preference for the elderly.

\section{CONFLICTS OF INTEREST}

The authors declared no conflict of interest.

\section{AUTHORSHIP}

Study conception and design acquisition - PH and PMJ; Data collection - PMJ; Analysis and interpretation of the data - $\mathrm{PH}$ and PMJ; Drafting - PMJ; Critical revision of the manuscript - PH; Final approval- $\mathrm{PH}$ and PMJ.

\section{ACKNOWLEDGEMENT}

This article is a revision of the first author's master's thesis from Keimyung University.

\section{REFERENCES}

1. Chao S-Y, Lan Y-H, Tso H-C, Chung C-M, Neim YM, Clark MJ. Predictors of psychosocial adaptation among elderly residents in long-term care settings. Journal of Nursing Research. 2008; 16(2):149-58.

https:// doi.org/10.1097/01.JNR.0000387300.22172.c6

2. Choi S-H, Yang H-W. Mental health of the Korean elderly and the Japanese elderly in institutions: focused on depression and stress. Journal of the Korea Gerontological Society. 2003;23(4): $129-47$.

3. Jackson B, Swanson C, Hicks LE, Prokop L, Laughlin J. Bridge of continuity from hospital to nursing home-Part 1 : a proactive approach to reduce relocation stress syndrome in the elderly. Continuum (Society for Social Work Leadership in Health Care). 2000;20(1):3-8.

4. Park M. Evidence-based stress management: focusing on nonpharmacological procedure which reduce stress and promote health. Journal of the Korean Medical Association. 2013;56(6): 478-84. https://doi.org/10.5124/jkma.2013.56.6.478

5. Kamel NS, Gammack JK. Insomnia in the elderly: cause, approach and treatment. The American Journal of Medicine. 2006;119(6):463-9.

https://doi.org/10.1016/j.amjmed.2005.10.051

6. Kim M-S, Kim J-I. Relationship among the health state, daily living activities (ADL, IADL), sleep state, and depression among old people at elderly care facilities. Journal of the Korea Academia-Industrial Cooperation Society. 2015;16(4):2609-19. https://doi.org/10.5762/KAIS.2015.16.4.2609

7. Seo SY, Chang SY. Effects of aroma hand massage on sleep, depression and quality of life in the institutionalized elderly women. Korean Journal of Women Health Nursing. 2009;15 (4):372-80.

8. Kim SJ. Pharmacotherapy of insomnia. Journal of the Korean Medical Association. 2009;52(7):719-26. https://doi.org/10.5124/jkma.2009.52.7.719

9. Buckle J. Literature review: should nursing take aromatherapy more seriously? British Journal of Nursing. 2007;16(2):116-20. https://doi.org/10.12968/bjon.2007.16.2.22772

10. Oh HK. Aromatherapy handbook. First ed. Seoul: Yangmun; 2002. p. 27.

11. Kang SJ, Kim NY. The effects of aroma hand massage on pruritus, fatigue and stress of hemodialysis patients. Korean Journal of Adult Nursing. 2008;20(6):883-94.

12. Setzer WN. Essential oils and anxiolytic aromatherapy. Natural Product Communications. 2009;4(9):1305-16.

13. Ali B, Al-Wabel NA, Shams S, Ahamad A, Khan SA, Anwar F. Essential oils used in aromatherapy: a systemic review. Asian Pacific Journal of Tropical Biomedicine. 2015;5(8):601-11. https://doi.org/10.1016/j.apjtb.2015.05.007

14. Kim HS, Kim SH, Park YS. Effects of aromatherapy on stress and depression of the institutionalized elderly. Poster session presented at: 2012 Korean Society of Nursing Science; 2012 October 26; The Korean Federation of Science and Technology Societies. Seoul.

15. Park SM. A study on the effect of aroma therapy with lavender oil on stress and depression of middle-aged women [master's thesis]. Daejeon: Daejeon University; 2005. p. 49-52.

16. Park JM. A study on the aroma essential oils use and preferences [master's thesis]. Seoul: Sungshin University; 2012.

17. Kim YH. Effect of aroma hand massage using lavender oil on improvement of sleep quality of the elderly inpatients [dissertation]. Daegu: Keimyung University; 2010.

18. Park SY. Stress and my health. Gwangju-city Sea-gu Health News. 1999;11(84):7-9.

19. Oh JJ, Song MS, Kim SM. Development and validation of Korean Sleep Scale A. Journal of Korean Academy of Nursing. 1998;28(3):563-72. https://doi.org/10.4040/jkan.1998.28.3.563 
20. Snyder-Halpern R, Verran JA. Instrumentation to describe subjective sleep characteristics in healthy subjects. Research in Nursing \& Health. 1987;10(3):155-63. https://doi.org/10.1002/nur.4770100307

21. Lee JE, Lee YW, Kim H. Effects of aroma hand massage on the stress response and sleep of elderly inpatients. Journal of Korean Academy of Fundamentals of Nursing. 2011;18(4):480-7.

22. Korean Nurses Association. Progress of aromatherapy. Seoul: Korean Nurses Association; 2004.

23. Tang SK, Tse MY. Aromatherapy: does it help to relieve pain, depression, anxiety, and stress in community-dwelling older persons? BioMed Research International. 2014;2014:430195. https://doi.org/10.1155/2014/430195

24. Toda M, Morimoto K. Effect of lavender aroma on salivary endocrinological stress markers. Archives of Oral Biology. 2008; 53(10):964-8.

https://doi.org/10.1016/j.archoralbio.2008.04.002

25. Bikmoradi A, Seifi Z, Poorolajal J, Araghchian M, Safiaryan R, Oshvandi K. Effect of inhalation aromatherapy with lavender essential oil on stress and vital signs in patients undergoing coronary artery bypass surgery: a single-blinded randomized clinical trial. Complementary Therapies in Medicine. 2015;23
(3):331-8. https://doi.org/10.1016/j.ctim.2014.12.001

26. Hirokawa K, Nishimoto T, Taniguchi T. Effects of lavender aroma on sleep quality in healthy Japanese students. Perceptual and Motor skills. 2012;114(1):111-22.

https://doi.org/10.2466/13.15.PMS.114.1.111-122

27. Lee SY. The effect of aromatherapy hand massage on stress, depression and sleep disturbance of the institutionalized elderly. Korean Journal of Health Promotion and Disease Prevention. 2008;8:40-8.

28. Moeini M, Khadibi M, Bekhradi R, Mahmoudian SA, Nazari F. Effect of aromatherapy on the quality of sleep in ischemic heart disease patients hospitalized in intensive care units of heart hospitals of the Isfahan University of Medical Sciences. Iranian Journal of Nursing and Midwifery Research. 2010;15(4):234-9.

29. Lytle J, Mwatha C, Davis KK. Effect of lavender aromatherapy on vital signs and perceived quality of sleep in the intermediate care unit: a pilot study. American Journal of Critical Care. 2014;23(1):24-9. https:// doi.org/10.4037/ajcc2014958

30. Koh H-J. Review on the emotional effect of aromatherapy. Korean Journal of Aesthetics and Cosmetology. 2006;4(2): 129-41. 